\title{
ARTICLE
}

반응표면분석을 활용한 균질 효율 예측

강호진 $\cdot$ 강신호 - 신용국

서울우유협동조합 중앙연구소

\section{Prediction of Homogenization Efficiency using Response Surface Methodology}

\author{
Ho Jin Kang*, Shin Ho Kang, and Yong Kook Shin \\ R\&D Center, Seoul Dairy Cooperative
}

Received: September 18, 2017

Revised: September 25, 2017

Accepted: September 26, 2017

*Corresponding author :

Ho Jin Kang

R\&D Center, Seoul Dairy Cooperative, Ansan, Korea.

Tel :+82-31-481-0111

Fax :+82-31-491-9179

E-mail : hojin9045@seoulmilk.co.kr

Copyright $\odot 2017$ Korean Society of Milk Science and Biotechnology.

This is an Open Access article distributed under the terms of the Creative Commons Attribution Non-Commercial License (http:/l creativecommons.org/ licenses/by-nc/3.0) which permits unrestricted non-commercial use, distribution, and reproduction in any medium, provided the original work is properly cited.

\begin{abstract}
The objective of this study was to analyze the effects of homogenization, storage temperature, and storage period on the creaming of milk fat and changes in fat contents in the upper and lower layers and to predict the conditions for optimal homogenization efficiency using response surface methodology (RSM). The homogenization pressure, storage temperature, and storage period were set as independent variables of RSM, and the dependent variables were creaming, US Public Health Service (USPHS) code, and volume weighted mean diameter $\left(\mathrm{D}_{4,3}\right)$ in the upper and lower layers. Based on the results of RSM and regression analysis, the correlation coefficient $\left(R^{2}\right)$ between experimental data and predicted values by RSM for homogenized milk was estimated to be more than 0.8. The RSM analysis indicated that optimal homogenization pressures of $14 \mathrm{MPa}$ or more and $17 \mathrm{MPa}$ or more were required to maintain the creaming layer of $3 \mathrm{~mm}$ or less during the storage for 15 days at $10^{\circ} \mathrm{C}$ and $20^{\circ} \mathrm{C}$, respectively. To keep the USPHS code at less than $10 \%$ for 15 days at $10^{\circ} \mathrm{C}$ and $20^{\circ} \mathrm{C}$, milk should be homogenized with a pressure of $16.8 \mathrm{MPa}$ or more and $17 \mathrm{MPa}$ or more, respectively.
\end{abstract}

\section{Keywords}

homogenization, USPHS code, NIZO value, creaming, milk fat globule size, response surface methodology

\section{서 론}

목장에서 집유된 우유는 균질 공정을 거친 후, 살균 - 냉각 공정으로 진행된다. 균질 공정은 원유의 지방구의 크기를 0.5 1 $\mu \mathrm{m}$ 의 일정한 크기로 작게 만들어주는데 균질 공정의 장점으로는 지방구의 전체 표면적을 증가시켜 지방의 크림화 지연, 빛 반사 증가, 맛과 조직감 향상, 소화율을 증가시킨다 (Spreer, 1998). 반면에 균질 공정의 단점으로는 증가된 표면적으로 인한 미생물의 지방 분해 효소에 의한 산화, 빛에 의한 광산화, 미생물 오염 증가, 단백질의 열 안정성 감소 등이 있다(Spreer, 1998). 우유 제품의 균질 후, 지방구의 크기는 제품의 유통기한에 영향을 준다. Spreer(1998)는 신선한 우유 의 경우에는 며칠간의 크림화를 회피하기 위해서는 $1.0 \sim 1.5 \mu \mathrm{m}$ 의 지방구 크기로 충분하지만, UHT 우유와 같은 긴 유통기간의 제품은 응집과 크림화를 방지하기 위해서 $0.2 \sim 0.7 \mu \mathrm{m}$ 의 지방구 크기를 목표로 한다고 기술하고 있다. Pandolfe(2005)는 목적으로 하는 유통기간에 따라 $\mathrm{D}_{4,3}$ (volume weighted mean diameter)과 균질압을 제시하고 있다. 유통기간 10 12일 경우에는 $\mathrm{D}_{4,3}$ 은 0.88 $0.80 \mu \mathrm{m}$, 균질압 $12.4 \sim 13.8 \mathrm{MPa}$, 유통기간 $13 \sim 15$ 일 경우에는 $\mathrm{D}_{4.3}$ 은 $0.78 \sim 0.72 \mu \mathrm{m}$, 균질압 $13.8 \sim 16.5 \mathrm{MPa}$, 유통기간 16 20일 경우에는 $\mathrm{D}_{4,3}$ 은 0.70 0.63 $\mu \mathrm{m}$, 균질압 $16.8 \sim 18.5 \mathrm{MPa}$, 유통기한 21 30일 경우에는 $\mathrm{D}_{4.3}$ 은 0.61 0.51 $\mu \mathrm{m}$, 균질압 20.7 31 MPa로 기술하고 있다. 
균질 효율을 측정하는 방법으로는 microscopic method, storage methods, centrifugal methods가 있다(Ridgway, 1957). Microscopic method는 현미경으로 $2 \mu \mathrm{m}$ 이하인 지방구 수를 계수하여 균질 효율을 측정한다. Storage methods는 USPHS code와 burette method가 있는데, 균질한 우유를 일정 시간 정치한 후, 상부 $100 \mathrm{~mL}$ 의 우유의 지방 함량과 나머지 여액의 지방 함량을 측정하여 균질 효율을 계산한다. USPHS code는 48시간 정치하고, burette method는 72시간 정치한다. Centrifugal methods는 American method와 English method가 있는데, 전자는 우유 $50 \mathrm{~mL}$ 를 $1,500 \mathrm{rpm}$ 으로 10 분 동안 원심분리한 후, 상등액 $10 \mathrm{~mL}$ 는 버리 고, 여액 중 $9 \mathrm{~mL}$ 를 샘플링하여 지방을 측정하여 균질 효율을 계산 한다. 후자는 균질한 우유 $50 \mathrm{~mL}$ 를 30 분간 원심분리한 후, 아래쪽 $11 \mathrm{~mL}$ 의 우유를 샘플링하여 지방 함량을 측정하고, 균질 효율을 계 산한다.

균질 효율에 대한 판단으로 USPHS code에서는 상층부 지방 함량과 나머지 부분의 지방 함량 차이 값이 $10 \%$ 보다 작아야 된다(Ridgway, 1957). English method는 NIZO method로 더 알려져 있는데, 10 14일의 유통기한인 우유는 70\% 정도의 NIZO value가 측정되 어야 하고, 3 6개월의 유통기한인 UHT 우유는 $85 \%$ 이상의 NIZO value가 측정되어야 한다(Tetra Pak, 2017).

균질 효율을 측정하는 방법은 다양하지만, 균질 조건, 저장 온도, 저 장 기간 등이 유지방의 크림화 정도와 어떤 연관성이 있는지에 대한 연구 보고는 찾기가 어렵다. 따라서 본 연구에서는 반응표면분석법 을 활용하여 균질 조건, 저장 온도, 저장 기간 등이 유지방의 크림화 와 상층부와 하층부의 지방 함량 변화 등에 대해 미치는 영향을 분석 하고, 최적의 균질 효율을 갖는 조건들을 예측하고자 실시하였다.

\section{재료 및 방법}

\section{1. 우유의 제조}

원유는 서울우유 안산공장에서 수유된 원유를 사용하였고, 미생 물 증식을 억제하기 위해 원유에 sodium azide를 $0.02 \%(\mathrm{w} / \mathrm{v})$ 첨 가하였다. Table 3 의 실험 조건에 따라 원유는 $65^{\circ} \mathrm{C}$ 로 가온한 후, two stage 균질기인 APV 1000(Denmark)으로 균질하고, 일반적 우유의 열처리 조건인 $\mathrm{F}_{0}=2$ 에 맞추기 위해 $97^{\circ} \mathrm{C}$ 수욕조에서 39 분 동안 열처리 후, 냉각하였다.

\section{2. 균질 효율 측정}

균질 효율 측정은 USPHS code에 의한 방법(Ridgway, 1957)과 NIZO value에 의한 방법(Tetra Pak, 2017)으로 측정하였다. USPHS code는 $1 \mathrm{~L}$ 시료를 48시간 방치하여 상층부의 $100 \mathrm{~mL}$ 지방 함량 과 나머지 부분의 유지방 함량을 Milkoscan(FT2, Foss, Denmark) 으로 측정하였다.
$\operatorname{USPHS}(\%)=\frac{\left(F_{t}-F_{b}\right)}{F_{t}} \times 100$

$\mathrm{F}_{\mathrm{t}}:$ Fat percentage in top $100 \mathrm{~mL}$

$\mathrm{F}_{\mathrm{b}}$ : Fat percentage in the remainder of flask

$\mathrm{NIZO}$ value 측정은 원심분리용 튜브에 시료 $25 \mathrm{~mL}$ 를 넣고, $40^{\circ} \mathrm{C}$ 수욕조에 10 분간 방치한 후, $1,000 \mathrm{rpm}, 30$ 분간 원심분리하고, 아 래쪽 $20 \mathrm{~mL}$ 시료와 원심분리 전 시료의 지방 함량을 Milkoscan (FT2, Foss, Denmark)으로 측정하였다.

Fat content in bottom $20 \mathrm{~mL}$ of

$\mathrm{NIZO}(\%)=\frac{\text { centerifuged sample }}{\text { Fat content in non-centrifuged sample }} \times 100$

\section{3. 크림화 측정}

저장 중의 우유의 크림화 정도(creaming)는 Lu 등(2013)의 방법에 준하여 실시하였다. 시료를 $100 \mathrm{~mL}$ 메스실린더에 채우고, $10^{\circ} \mathrm{C}, 15^{\circ} \mathrm{C}$, $20^{\circ} \mathrm{C}$ 에서 저장하면서 상층부에 형성된 크림층을 측정하였다. 메스실 린더를 3등분하여 상층부 $30 \mathrm{~mL}$ 와 하층부 $30 \mathrm{~mL}$ 의 지방 함량을 Milkoscan(FT2, Foss, Denmark)으로 측정하고(Lu et al., 2013), USPHS code를 계산하였다.

\section{4. 유유 지방구 크기 측정}

우유 지방구 크기는 레이저 입도 회절 측정기인 Mastersizer 3000 (Malvern Instrument Ltd., UK)을 사용하였고, particle refractive index는 1.458, dispersant refractive index는 1.330, particle absorption index는 0.01, laser obscurations은 1 8\%을 적용하였다(Huppertz et al., 2003; Marzo et al., 2016). 제품 제 조 후, 우유 지방구 크기를 측정하고, 메스실린더에 저장한 시료의 상층부와 하층부의 우유 지방구 크기를 측정하였다.

\section{5. 통계처리}

모든 측정은 3반복을 실시하였고, Minitab 14(Minitab Inc., State College, PA)을 이용하여 중심합성계획법(central composite design) 에 따라 Table 2 와 같이 설계하여 반응표면분석법(RSM, response surface methodology)으로 분석하였다. 독립변수 $\left(X_{i}\right)$ 는 균질압, 저 장 온도 저장 기간으로 선정하였고, 종속변수 $(Y)$ 는 creaming, USPHS code, $\mathrm{D}_{4,3}$ 를 선정하였다. 독립변수와 종속변수에 대한 2 차 회귀모 형식을 도출하였으며, $\beta_{0}$ 는 상수이고, $\beta_{i}, \beta_{i i}, \beta_{i j}$ 는 회귀계수이다.

$$
Y=\beta_{0}+\sum_{i=1}^{k} \beta_{i} X_{i} \sum_{i=1}^{k} \beta_{i i} X_{i}^{2}+\sum_{i=1}^{k-1} \sum_{j=i+1}^{k} \beta_{i j} X_{i} X_{j}
$$

실험 데이터와 반응표면분석법에 의해 산출된 예측치에 대해서는 
Table 1. USPHS code, NIZO value, and $D_{4,3}$ of homogenized milk

\begin{tabular}{cccc}
\hline Homogenization & \multicolumn{3}{c}{ Homogenization pressure(MPa) } \\
\cline { 2 - 4 } efficiency & 10 & 20 & 30 \\
\hline USPHS(\%) & $4.81 \pm 0.456$ & $0.65 \pm 0.559$ & $0.08 \pm 0.141$ \\
NIZO $(\%)$ & $74.35 \pm 1.668$ & $94.77 \pm 0.283$ & $98.45 \pm 1.258$ \\
$D_{4,3}(\mu \mathrm{m})$ & $1.01 \pm 0.0058$ & $0.69 \pm 0.002$ & $0.565 \pm 0.020$ \\
\hline
\end{tabular}

* Values are mean $\pm \mathrm{SD}(n=3)$.

Table 2. Experimental range and value of the independent variables on the central composite design for homogenized milk

\begin{tabular}{ccccc}
\hline \multirow{2}{*}{$\mathrm{X}_{n}$} & \multirow{2}{*}{ Experimental condition } & \multicolumn{3}{c}{ Level } \\
\cline { 3 - 5 } & & -1 & 0 & 1 \\
\hline $\mathrm{X}_{1}$ & Homogenizer pressure(MPa) & 10 & 20 & 30 \\
$\mathrm{X}_{2}$ & Storage temp. $\left({ }^{\circ} \mathrm{C}\right)$ & 10 & 15 & 20 \\
$\mathrm{X}_{3}$ & Storage period(d) & 10 & 15 & 20 \\
\hline
\end{tabular}

Minitab 14(Minitab Inc., State College, PA)을 사용하여 회귀분 석을 실시하였다.

\section{결과 및 고찰}

\section{1. 균질 효율 측정}

USPHS code, NIZO value와 우유 지방구의 $\mathrm{D}_{4,3}$ 측정 결과는 Ta- ble 1 과 같다. $10 \mathrm{MPa}, 20 \mathrm{MPa}, 30 \mathrm{MPa}$ 로 균질한 우유의 USPHS code는 $4.81 \%, 0.65 \%, 0.08 \%$ 으로, 균질의 적합성을 판단하는 기준 인 10\% 미만(Ridgway, 1957)을 만족하였다. NIZO value는 $74.35 \%$, $94.77 \%, 98.45 \%$ 로 측정되었는데, 10 14일의 유통기간인 우유는 $70 \%$ 정도의 $\mathrm{NIZO}$ 값을, 3 6개월의 유통기간인 UHT 우 유는 85\% 이상의 NIZO 값을 갖는다(Tetra Pak, 2017). 제시된 기준에 따르 면, $10 \mathrm{MPa}$ 로 균질한 우유는 적어도 14 일 이상의 유통기간이 가능 하고, $20 \mathrm{MPa}$ 와 $30 \mathrm{MPa}$ 로 균질한 우유는 3 6개월의 유통기간이 가능하다. Pandolfe(2005)의 기준에 의하면 10 12일의 유통기한 인 우유의 $\mathrm{D}_{4,3}$ 은 0.88 0.80 $\mu \mathrm{m}$ 이지만, $10 \mathrm{MPa}$ 의 $\mathrm{D}_{4,3}$ 은 1.007 $\mu \mathrm{m}$ 로 10 일의 유통기한도 불가능하다. $20 \mathrm{MPa}$ 의 $\mathrm{D}_{4,3}$ 은 $0.690 \mu \mathrm{m}$ 으로 16 20일의 유통기한이 가능하고, $30 \mathrm{MPa}$ 의 $\mathrm{D}_{4,3}$ 은 $0.555 \mu \mathrm{m}$ 로 21 30일의 유통기한이 가능하다.

\section{2. 반응표면분석법에 의한 모델 구축}

Table 2에 따라 설계한 독립변수 $\left(\mathrm{X}_{j}\right)$, 균질압력, 저장 온도, 저장 기 간에 대한 종속변수 $\left(\mathrm{Y}_{i}\right)$ creaming, USPHS code, 상층부의 $\mathrm{D}_{4,3}$, 하층부의 $\mathrm{D}_{4,3}$ 을 예측하기 위해 반응표면분석법을 사용하였다. 각 독 립변수를 $-1,0,1$ 의 3 수준으로 부호화하여 20개의 실험구를 설계 하여 Table 3과 같이 실험을 실시하였다.

저장 중 크림화 정도를 측정한 creaming은 1 6 mm의 측정 결과

Table 3. Experimental combination and data under various condition of homogenization pressure, storage temperature, storage period, and their responses

\begin{tabular}{|c|c|c|c|c|c|c|c|}
\hline Run & $\begin{array}{c}\text { Homogenizer } \\
\text { pressure }(\mathrm{MPa}) \\
\mathrm{X}_{1} \\
\end{array}$ & $\begin{array}{c}\text { Storage temp. } \\
\left({ }^{\circ} \mathrm{C}\right) \\
\mathrm{X}_{2}\end{array}$ & $\begin{array}{c}\text { Storage period } \\
\text { (d) } \\
X_{3}\end{array}$ & $\begin{array}{c}\text { Creaming } \\
(\mathrm{mm}) \\
\mathrm{Y}_{1} \\
\end{array}$ & $\begin{array}{c}\text { USPHS } \\
(\%) \\
Y_{2} \\
\end{array}$ & $\begin{array}{c}\text { Top } \\
\mathrm{D}_{4,3}(\mu \mathrm{m}) \\
\mathrm{Y}_{3} \\
\end{array}$ & $\begin{array}{c}\text { Bottom } \\
\mathrm{D}_{4,3}(\mu \mathrm{m}) \\
\mathrm{Y}_{4} \\
\end{array}$ \\
\hline 1 & 10 & 15 & 15 & 5 & 38.91 & 1.103 & 0.823 \\
\hline 2 & 10 & 10 & 10 & 5 & 30.12 & 1.113 & 0.972 \\
\hline 3 & 20 & 15 & 15 & 1 & 8.55 & 0.695 & 0.650 \\
\hline 4 & 20 & 10 & 15 & 1 & 3.55 & 0.669 & 0.641 \\
\hline 5 & 10 & 10 & 20 & 5 & 36.36 & 1.150 & 0.869 \\
\hline 6 & 20 & 15 & 20 & 2 & 7.84 & 0.758 & 0.665 \\
\hline 7 & 30 & 15 & 15 & 1 & 2.63 & 0.553 & 0.539 \\
\hline 8 & 20 & 15 & 15 & 2 & 6.99 & 0.702 & 0.698 \\
\hline 9 & 20 & 15 & 15 & 2 & 6.56 & 0.770 & 0.688 \\
\hline 10 & 10 & 20 & 20 & 6 & 59.62 & 0.982 & 0.674 \\
\hline 11 & 30 & 10 & 10 & 1 & 0.73 & 0.542 & 0.542 \\
\hline 12 & 20 & 15 & 15 & 2 & 6.78 & 0.963 & 0.632 \\
\hline 13 & 30 & 20 & 10 & 1 & 4.09 & 0.549 & 0.540 \\
\hline 14 & 20 & 15 & 15 & 2 & 5.88 & 0.669 & 0.677 \\
\hline 15 & 30 & 10 & 20 & 1 & 1.96 & 0.553 & 0.553 \\
\hline 16 & 20 & 20 & 15 & 3 & 15.73 & 0.812 & 0.680 \\
\hline 17 & 30 & 20 & 20 & 3 & 8.55 & 0.563 & 0.517 \\
\hline 18 & 20 & 15 & 10 & 1 & 5.65 & 0.679 & 0.673 \\
\hline 19 & 20 & 15 & 15 & 2 & 6.98 & 0.706 & 0.679 \\
\hline 20 & 10 & 20 & 10 & 5 & 48.69 & 1.070 & 0.787 \\
\hline
\end{tabular}


를 보였고, 균질압이 높을수록, 보존 온도가 낮을수록, 저장 기간이 짧을수록 creaming 수치는 낮게 측정되었다. Creaming에 대해서 독립변수의 선형, 제곱, 상호작용에 대해 반응표면분석을 수행하였 다. 추정된 회귀 계수 중 $p$ 값이 0.05 보다 큰 항 $\mathrm{X}_{2}^{2}(p=0.181)$, $\mathrm{X}_{3}^{2}(p=0.602), \mathrm{X}_{1} \mathrm{X}_{2}(p=0.419), \mathrm{X}_{1} \mathrm{X}_{3}(p=0.419)$ 을 제외시키고, $\mathrm{Y}_{1}$ $=12.2750-0.079 \mathrm{X}_{1}-0.125 \mathrm{X}_{2}-0.145 \mathrm{X}_{3}+0.00015 \mathrm{X}_{1}^{2}+0.015 \mathrm{X}_{2}$ $X_{3}$ 의 모델식을 산출하였다. $R^{2}$ 값은 0.957 이고, $p$ 값은 $<0.0001$ 로 유의성이 인정되었으며, 적합성 결여의 $p$ 값은 0.517 로 0.05 보다 큰 값을 가지므로 반응표면분석에서 얻어진 모델은 적절한 것으로 확인되었다.

저장 중 상층부와 하층부의 지방 함량을 측정하여 산출한 USPHS code는 0.73 59.62\%의 결과를 보였다. $10 \mathrm{MPa}$ 의 압력으로 균질 한 우유는 $10^{\circ} \mathrm{C}$ 에서 10 일간 저장한 제품도 $30.12 \%$ 의 결과를 보였 고, $20 \mathrm{MPa}$ 의 압력에서 균질한 우유 중에서는 $20^{\circ} \mathrm{C}$ 에서 15 일간 저 장한 제품이 $15.73 \%$ 로 가장 높은 결과를 보였다. $30 \mathrm{MPa}$ 로 균질한 우유 중에서는 $20^{\circ} \mathrm{C}$ 에서 20 일간 저장한 제품이 $8.55 \%$ 로 가장 높았 고, $10^{\circ} \mathrm{C}$ 에서 10 일간 저장한 제품은 $0.73 \%$ 로 가장 낮은 결과를 보 였다. 독립변수의 선형, 제곱, 상호작용에 대해 반응표면분석을 수행 하여 도출한 회귀 계수 중에서 $p$ 값이 0.05 보다 큰 항 $\mathrm{X}_{3}^{2}(p=0.924)$ 을 제외시키고, $\mathrm{Y}_{2}=77.4610-0.5596965 \mathrm{X}_{1}-1.07955 \mathrm{X}_{2}-0.486 \mathrm{X}_{3}+$ $0.00139331 \mathrm{X}_{1}^{2}+0.112125 \mathrm{X}_{2}^{2}-0.00772 \mathrm{X}_{1} \mathrm{X}_{2}-0.00262 \mathrm{X}_{1} \mathrm{X}_{3}+$ $0.0346 \mathrm{X}_{2} \mathrm{X}_{3}$ 의 모델식을 산출하였다. $R^{2}$ 값은 0.998 이고, $p$ 값은 $<0.0001$ 로 유의성이 인정되며, 적합성 결여의 $p$ 값은 0.246 으로 0.05 보다 큰 값을 가지므로 반응표면분석에서 얻어진 모델은 적절한 것으로 확인되었다.

지방구 크기는 부피로 산출한 평균 직경인 $\mathrm{D}_{4,3}$ 을 측정하였다. 10 $\mathrm{MPa}$ 로 균질하여 보존한 우유 상층부의 $\mathrm{D}_{4,3}$ 은 $0.982 ~ 1.150 \mu \mathrm{m}$, 하층부의 $\mathrm{D}_{4,3}$ 은 $0.674 \sim 0.972 \mu \mathrm{m}$ 였고, $20 \mathrm{MPa}$ 로 균질하여 보존 한 우유의 상층부의 $\mathrm{D}_{4,3}$ 은 0.669 0.963 $\mu \mathrm{m}$, 하층부의 $\mathrm{D}_{4,3}$ 은 0.632 0.698 $\mu \mathrm{m}, 30 \mathrm{MPa}$ 로 균질하여 보존한 우유의 상층부의 $\mathrm{D}_{4,3}$ 은 $0.542 \sim 0.563 \mu \mathrm{m}$, 하층부의 $\mathrm{D}_{4,3}$ 은 $0.517 \sim 0.553 \mu \mathrm{m}$ 이었 다. 상층부의 $\mathrm{D}_{4,3}$ 의 독립변수의 선형, 제곱, 상호작용에 대해 반응표 면분석을 수행하여 도출한 회귀 계수 중에서 $p$ 값이 0.05보다 큰 항 $\mathrm{X}_{1}^{2}(p=0.133), \mathrm{X}_{2}^{2}(p=0.992), \mathrm{X}_{3}^{2}(p=0.699), \mathrm{X}_{1} \mathrm{X}_{2}(p=0.388)$, $\mathrm{X}_{1} \mathrm{X}_{3} \quad(p=0.770), \mathrm{X}_{2} \mathrm{X}_{3}(p=0.640)$ 을 제외시키고, $\mathrm{Y}_{3}=1.31105-$ $0.002658 \mathrm{X}_{1}-0.00102 \mathrm{X}_{2}-0.00106 \mathrm{X}_{3}$ 의 모델식을 산출하였다. $R^{2}$ 값 은 0.856 이고, $p$ 값은 $<0.0001$ 로 유의성이 인정되었으며, 적합성 결 여의 $p$ 값은 0.873 으로 0.05 보다 큰 값을 가지므로 반응표면분석에 서 얻어진 모델은 적절한 것으로 확인되었다. 하층부의 $\mathrm{D}_{4,3}$ 의 독립 변수의 선형, 제곱, 상호작용에 대해 반응표면분석을 수행하여 도출 한 회귀 계수 중에서 $p$ 값이 0.05 보다 큰 항 $\mathrm{X}_{1}^{2}(p=0.499), \mathrm{X}_{2}^{2}(p=$ $0.798), X_{3}^{2}(p=0.894), X_{2} X^{3}(p=0.668)$ 을 제외시키고, $Y_{4}=1.55575-$ $0.0034815 \mathrm{X}_{1}-0.02468 \mathrm{X}_{2}-0.001492 \mathrm{X}_{3}+0.0000855 \mathrm{X}_{1} \mathrm{X}_{2}+0.00$
$0051 \mathrm{X}_{1} \mathrm{X}_{3}$ 의 모델식을 산출하였다. $R^{2}$ 값은 0.947 이고, $p$ 값은 < 0.0001 로 유의성이 인정되었으며, 적합성 결여의 $p$ 값은 0.247 로 0.05 보다 큰 값을 가지므로 반응표면분석에서 얻어진 모델은 적절한 것으로 확인되었다.

\section{3. 반응표면분석법을 이용한 결과값의 최적화}

각 실험구의 데이터와 반응표면분석법에 의해 산출된 예측값에 대한 회귀분석 결과는 Table 4 와 같다. Creaming 회귀모델의 상관계수 (correlation coefficient)인 $R^{2}$ 는 0.957 이고, 수정 $R^{2}$ 은 0.954 , 예측 $R^{2}$ 은 0.9451 이었다. USPHS code 회귀모델의 상관계수 $R^{2}$ 는 0.993 , 수정 $R^{2}$ 은 0.993 , 예측 $R^{2}$ 은 0.9856 이고, 상층부 $\mathrm{D}_{4,3}$ 회귀 모델의 상관계수 $R^{2}$ 는 0.856 , 수정 $R^{2}$ 은 0.848 , 예측 $R^{2}$ 은 0.8304 , 하층부 $\mathrm{D}_{4,3}$ 회귀모델의 결정계수 $R^{2}$ 는 0.947 , 수정 $R^{2}$ 은 0.944 , 예 측 $R^{2}$ 은 0.9367 이었다. 회귀모델에서 입력 변수가 증가하면 $R^{2}$ 도 증가하는데 이러한 단점을 보완해 주는 것이 수정 $\mathrm{R}^{2}$ 이고, 예측 $R^{2}$ 은 회귀모델에서 새로운 관측치에 대한 반응을 예측하는 정도를 보 여주며, 수정 $R^{2}$ 과 예측 $R^{2}$ 은 0.2 미만의 차이를 보여야 한다(Mohan et al., 2016). 결과적으로 실험치와 예측치의 회귀모델은 통계 적으로 유의하며, 수정 $R^{2}$ 과 예측 $R^{2}$ 은 0.2 미만의 차이를 보였다. Fig. 1은 creaming에 대해 균질압과 저장 온도, 균질압과 저장 기간,

Table 4. Regression analysis between experimental data and predicted values by RSM program for homogenized milk

\begin{tabular}{ccccc}
\hline Run & Creaming $(\mathrm{mm})$ & USPHS(\%) & Top $\mathrm{D}_{4,3}(\mu \mathrm{m})$ & Bottom $\mathrm{D}_{4,3}(\mu \mathrm{m})$ \\
\hline 1 & 5.2 & 40.2975 & 1.04585 & 0.81835 \\
2 & 4.675 & 30.0946 & 1.04565 & 0.9481 \\
3 & 1.8 & 6.8904 & 0.78005 & 0.67495 \\
4 & 1.3 & 3.3975 & 0.78515 & 0.71285 \\
5 & 4.725 & 35.7946 & 1.05625 & 0.8499 \\
6 & 2.2 & 9.2954 & 0.78535 & 0.65135 \\
7 & 1.4 & 1.3495 & 0.51425 & 0.53155 \\
8 & 1.8 & 6.8904 & 0.78005 & 0.67495 \\
9 & 1.8 & 6.8904 & 0.78005 & 0.67495 \\
10 & 6.475 & 57.8366 & 1.04605 & 0.6886 \\
11 & 0.875 & 1.4866 & 0.51405 & 0.5248 \\
12 & 1.8 & 6.8904 & 0.78005 & 0.67495 \\
13 & 1.125 & 4.6286 & 0.50385 & 0.5345 \\
14 & 1.8 & 6.8904 & 0.78005 & 0.67495 \\
15 & 0.925 & 1.9466 & 0.52465 & 0.5286 \\
16 & 2.3 & 15.9895 & 0.77495 & 0.63705 \\
17 & 2.675 & 8.5486 & 0.51445 & 0.5383 \\
18 & 1.4 & 4.4854 & 0.77475 & 0.69855 \\
19 & 1.8 & 6.8904 & 0.78005 & 0.67495 \\
20 & 4.925 & 48.6766 & 1.03545 & 0.7868 \\
$R^{2}$ & 0.957 & 0.993 & 0.856 & 0.947 \\
$R_{\text {adj }}^{2}$ & 0.954 & 0.993 & 0.848 & 0.944 \\
$R_{\text {pred }}^{2}$ & 0.9451 & 0.9856 & 0.8304 & 0.9367 \\
$p$ & $<0.0001$ & $<0.0001$ & $<0.0001$ & $<0.0001$ \\
\hline & & & &
\end{tabular}




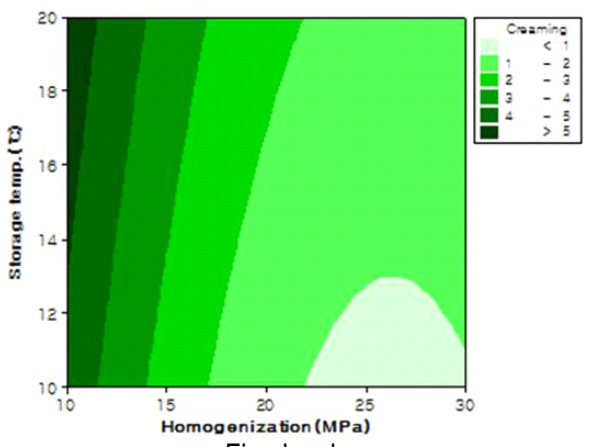

Fixed value

Storage period : $15 \mathrm{~d}$

(a)

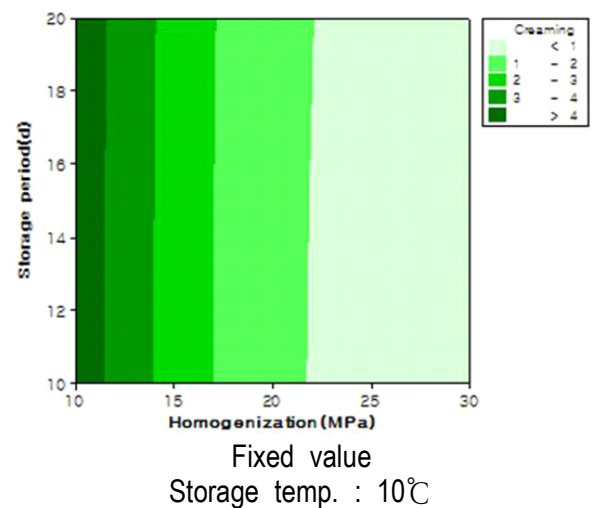

(b)

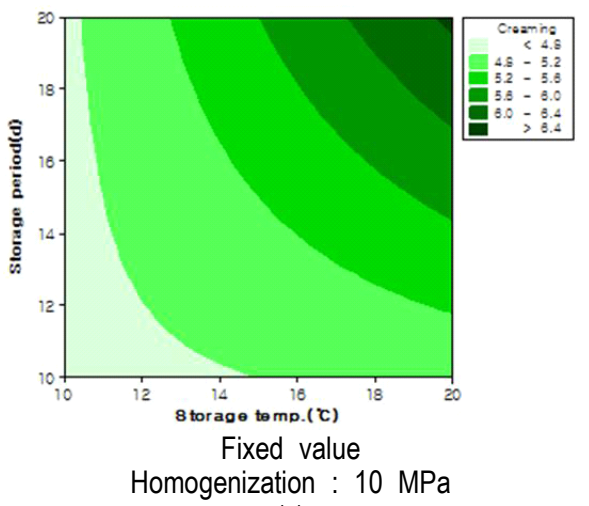

(c)

Fig. 1. Contour plot of creaming response for change in homogenization pressure, storage temperature, and storage period. (a) homogenization and storage temperature; (b) homogenization and storage period; (c) storage temperature and storage period.

저장 온도와 저장 기간에 대한 등고선도를 나타내었다. Fig. 1의 (a), (b) 등고선도에서 균질압이 증가할수록 creaming은 낮아지는 것을 볼 수 있다. $20 \mathrm{MPa}$ 로 균질한 우유의 creaming의 가장 높은 결과 인 $3 \mathrm{~mm}$ 를 기준으로 각 등고선도를 비교해 보면 다음과 같다. 저장 기간을 15 일로 고정했을 때, 저장 온도 $10^{\circ} \mathrm{C}$ 에서 $3 \mathrm{~mm}$ 이하의 creaming을 유지하기 위해서는 $14 \mathrm{MPa}$ 이상의 균질압이 요구되 고, 저장 온도 $20^{\circ} \mathrm{C}$ 에서 $3 \mathrm{~mm}$ 이하의 creaming을 유지하기 위해 서는 $17 \mathrm{MPa}$ 이상의 균질압이 요구된다. 저장 온도를 $10^{\circ} \mathrm{C}$ 로 고정 했을 때, 10 일간 $3 \mathrm{~mm}$ 이하의 creaming을 유지하기 위해서는 $13.9 \mathrm{MPa}$ 이상의 균질압이 요구되고, 20 일간 $3 \mathrm{~mm}$ 이하의 creaming을 유지하기 위해서는 $14 \mathrm{MPa}$ 이상의 균질압이 요구된다. 균 질압을 $10 \mathrm{MPa}$ 로 고정했을 때에는 등고선도에서 $10^{\circ} \mathrm{C}$ 에서 10 일 저 장했을 때, creaming은 $4.67 \mathrm{~mm}$ 정도이고, $20{ }^{\circ} \mathrm{C}$ 에서 20 일 저장 했을 때, creaming은 $6.47 \mathrm{~mm}$ 였다.

Fig. 2는 USPHS code에 대해 균질압과 저장 온도, 균질압과 저장 기간, 저장 온도와 저장 기간에 대한 등고선도를 보여준다. USPHS code $10 \%$ 미만에 대해 각 등고선도를 비교하면 다음과 같았다. 저 장기간을 15 일로 고정했을 때, 저장 온도 $10^{\circ} \mathrm{C}$ 에서는 $16.8 \mathrm{MPa}$ 정 도의 균질압이 요구되고, 저장 온도 $20^{\circ} \mathrm{C}$ 에서는 $23.1 \mathrm{MPa}$ 이상의 균질압이 요구된다. 저장 온도를 $10^{\circ} \mathrm{C}$ 로 고정했을 때, 10 일 저장 기 간에서는 $15.9 \mathrm{MPa}$ 이상이, 20 일의 저장기간에서는 $17.5 \mathrm{MPa}$ 이 상의 균질압이 필요하고, 균질압을 $10 \mathrm{MPa}$ 로 고정했을 때, $10^{\circ} \mathrm{C}$ 에 서 10 일 저장에서는 $30.11 \%, 20^{\circ} \mathrm{C}$ 에서 20 일간 저장했을 때에는 $57.72 \%$ 의 USPHS code가 예측되었다.

\section{요 약}

본 연구에서는 반응표면분석법을 활용하여 균질 조건, 저장 온도, 저 장 기간 등이 유지방의 크림화와 상층부와 하층부의 지방 함량 변화 등에 대해 미치는 영향을 분석하고, 최적의 균질 효율을 갖는 조건들 을 예측하고자 실시하였다. 반응표면분석법의 독립변수로는 균질압, 저장 온도, 저장 기간을 설정하였고, $-1,0,1$ 의 3 수준으로 20 개의

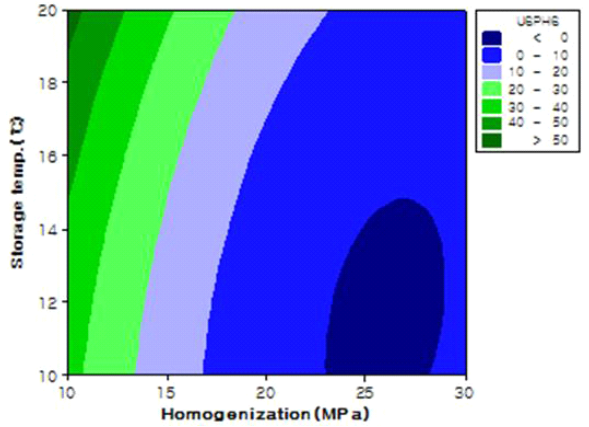

Fixed value Storage time : $15 \mathrm{~d}$

(a)

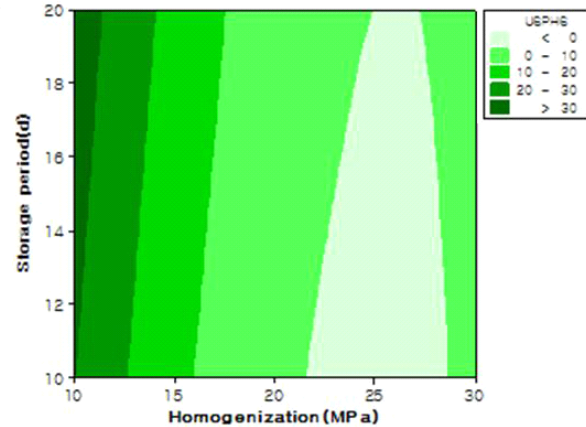

Fixed value Storage temp. : $10^{\circ} \mathrm{C}$

(b)

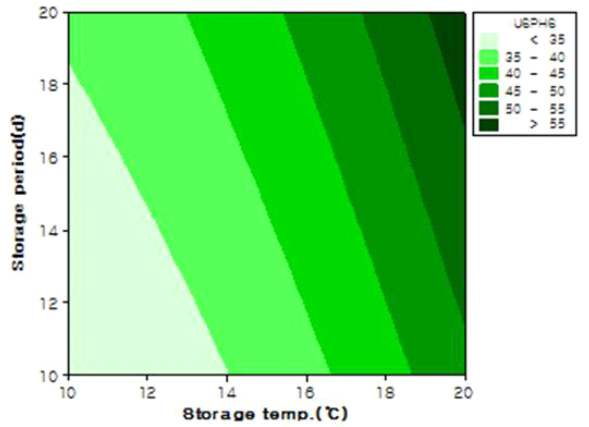

Fixed value Homogenization : $10 \mathrm{MPa}$

(c)

Fig. 2. Contour plot of USPHS response for change in homogenization pressure, storage temperature, and storage period. (a) homogenization and storage temperature; (b) homogenization and storage period; (c) storage temperature and storage period. 
실험구를 설계하여 종속변수인 creaming, USPHS code, 상층부의 $\mathrm{D}_{4,3}$, 하층부의 $\mathrm{D}_{4,3}$ 에 대해 실험을 실시하였다. 반응표면분석과 회 귀분석 결과, 균질한 우유의 실험 데이터와 RSM에 의해 예측된 값 들간의 상관계수는 0.8 이상의 상관성을 보였다. 반응표면분석의 최 적화 결과, $10^{\circ} \mathrm{C}$ 에서 15 일의 저장 기간 동안 $3 \mathrm{~mm}$ 이하의 크림화 를 유지하기 위해서는 $14 \mathrm{MPa}$ 이상의 균질압이 요구되고, $20^{\circ} \mathrm{C}$ 에 서 15 일의 저장 기간 동안 $3 \mathrm{~mm}$ 이하의 크림화를 유지하기 위해서 는 $17 \mathrm{MPa}$ 이상의 균질압이 요구된다. $10^{\circ} \mathrm{C}$ 에서 15 일의 저장 기간 동안 USPHS code를 $10 \%$ 미만으로 유지하기 위해서는 $16.8 \mathrm{MPa}$ 의 균질압이 요구되며, $20^{\circ} \mathrm{C}$ 에서 15 일 동안의 저장 기간을 유지하기 위해서는 $23.1 \mathrm{MPa}$ 의 균질압이 요구된다.

\section{References}

Huppertz, T., Fox, P. F. and Kelly, A. L. 2003. High pressureinduced changes in the creaming properties of bovine milk. Innov. Food Sci. Emerg. 4:349-359.

Lu, C., Wang, G., Li, Y. and Zhang, L. 2013. Effects of homogenization pressures on physicochemical changes in different layers of ultra-high temperature whole milk during storage. Int. J. Dairy Technol. 66:325-332.
Marzo, L. D., Patrick C., and Barbano, D. M. 2016. Prediction of fat globule particle size in homogenized milk using Fourier transform mid-infrared spectra. J. Dairy Sci. 99:8549-8560.

Mohan, C. C., Rakhavan, K. R., Krishnan, K. R., Babuskin, S., Sudharsan, K., Babu, P. A. S. and Sukumar, M. 2016. Development of predictive preservative model for shelf life parameters of beer using response surface methodology. LWT - Food Sci. Technol. 72:239-250.

Pandolfe, W. D. 2005. Estimating creaming rates for homogenized milk. SPX Technical Bulletin http://www.spxflow. com/en/assets/pdf/TB84_Rate_Of_Creaming_Milk_3088 _US_tcm11-7656.pdf

Ridgway, J. D. 1957. Tests for effectiveness of homogenization of milk. Int. J Dairy Technol. 10:214-218.

Spreer, E. 1998. Milk processing. Pages.89-94 in milk and dairy product technology. Marcel Dekker, Inc., New York, USA.

Tetra Pak. 2017. 4 important questions about NIZO. http:// processinginsights.tetrapak.com/4-important-questions -about-nizo-2. 